\title{
EQUITY RELATED CONCERNS: IMPACT OF PRIVATE TUTORING IN INDIA
}

\author{
HARSHITA SHARMA \\ National Institute of Educational Planning and Administration \\ 17-B, Sri Aurobindo Marg, NCERT Campus, New Delhi, Delhi-110016, India \\ E-mail address: harshita2792@gmail.com \\ ORCID number: https://orcid.org/0000-0001-9132-8148
}

\begin{abstract}
Aim. The paper attempts to explore the impact of private tutoring in light of the equity-related concerns especially in the context of the Indian society. Private tutoring is a phenomenon that has been an intrinsic part of the Indian education system since the 1980s.

Methods. The paper is an outcome of the Masters of Philosophy dissertation work of the scholar submitted to National University of Education Planning and Administration, Delhi, India.

Results. The structure of private tutoring is such that it mimics the regular school curriculum and modifies itself to match the needs of the school and the children. Any changes in the regular school curriculum bring a change in its supplement as well. It thus behaves like a shadow of the regular schools. Though private tutoring was believed to enhance learning opportunities of weak students, it has now become a 'parity of prestige' issue.

Conclusion. The expansion of tutoring has begun to deepen the inequalities already prevalent in the stratified schooling system and society at large.

Key words: parental involvement, school education, private supplementary tutoring, shadow education, equitable access, social mobility, comparative education, school culture, secondary education
\end{abstract}

\section{INTRODUCTION}

$\mathrm{O}$ ver the years, education has been understood as a means to enhance one's position in the society. Indian and international agencies have designed policies to support the expansion of education to all possible areas. Education is now considered to be a responsibility of state communities and individuals as it brings a change in the thought process and outlook of the individual and benefits the society at large. Although the state is mandated to provide free and compulsory education to all Indian citizens (Right to Education Act, 2009), it has somehow failed to provide quality education. This quality can be looked at in terms of learning outcomes, employment opportunities or both. Private 
parties have thus emerged, providing English medium education (which is the need of the global market), alongside a promise of better learning. These private bodies also assert that they are helping students become competitionready. There are multiple levels of competitions and examinations that an individual needs to face throughout his/her career, i.e. at school, at university (higher education) and on the job market. These competitions mostly favour rote learning rather than understanding and cognitive capacity testing, which creates a need to have institutions that help individuals get exam-ready. The private coaching or supplementary tutoring industry has flourished in this environment. It takes advantage of the insecurities of parents, their desires and aspirations for their child to stand out and be the best among the rest.

The large extent of private tutoring in India has been examined by many researchers, the consumption of this surrogate system ranges from $55 \%$ to $32.6 \%$ for many sampled Indian states (Sujatha, 2014). Here, surrogate system refers to private tuition in Indian scenario, where it is expected to take up the role of providing extra care to students by managing their studies in absence of their parents or in their incapacity to help their children perform well in public examinations (Sujatha, 2014). The national average is 37.8\%. According to the National Sample Survey (NSS) data cited in Mukut Hazarika \& Rima Kotaky (2016), one out of every four children, and in certain states, three out of every four children, receive private tutoring. In West Bengal, 71.1\% students at primary level and $89 \%$ of male secondary and higher secondary school students avail themselves of private tutoring. For a similar category of students, in Tripura, another Eastern state, the primary level tutoring goes up to $78.3 \%$ (Nanda, 2016). In West Bengal, the percentage of students receiving private tutoring in the fourth grade is $71.17 \%$, which accelerates to $93.35 \%$ as these children reach twelfth grade (State Council of Educational Research and Training [SCERT], West Bengal, 2009 report cited in Hazarika \& Kotaky, 2016).

An industry whose actual aim is to make others lag behind and push some to get an edge over the rest can be a threat to an equitable society from its very foundation. The paper unwraps this impact of the shadow of schooling system with a focus on the secondary and senior secondary level alongside addressing equity concerns. This level of schooling (unlike primary) is considered to be a baseline for the future of the child, as even the most misbehaved ones are expected to get serious and to endorse the testing culture in the hope of social mobility. According to K. Sujatha (2014), 44.7\% children were seeking private tutoring at higher secondary level, i.e. grade XI and XII, for at least one subject. Here again, a particular section of the society, i.e. the middle class is considered most aspirational (Sancho, 2015) as parents have some educational qualification and place a very high value on education. The South-Asian culture is such that it lays responsibilities for the child's education and future primarily on its parents, leading them to spend significant amounts on the child's education and especially on examination centred education (Bray, 1999). 


\section{EDUCATION AND SOCIAL MOBILITY}

Education is considered to be one of the most important determinants of social mobility. It provides empowerment to the individual intrinsically and on the other helps to provide opportunities for economic and social development. Olive Banks (1955) talks about the relation between secondary schools and the labour market in the post war analysis. According to him, the secondary education of a country has a direct link with the labour market, as it is expected to provide parity of prestige. The cultural and social capital institutes and societies provide help to the younger generation, allowing them to acquire a place for themselves in the labour market.

The differences in resources and prioritisation of education in family also are important determinants of educational success. Fiona Devine (2004) conducted a sociological comparative study showing that middle class doctor or teacher parents in Boston and Manchester often strive to get good jobs for their children. This trend is spreading as even families having bare minimum survival means hope for their children to get good education and procure a respectable position in the labour market. Craig Jeffrey, Patricia Jeffery and Roger Jeffery (2004) conducted a study that proves that education has begun to be appreciated by regional and cultural minorities as a means of cultural and social mobility. The Muslim minorities and Dalits see education as embodied distinction rather than a restriction to their cultural and social traditional indigenous identities.

In the context in which parents have such high hopes from education, they tend to increase their household share of expenditure on education. Also, a very recent phenomenon that has come to light is that public schools suffer from multiple problems like teacher absenteeism, insufficient English language teaching, poor infrastructure etc.; all these contribute to low quality education (Snehi, 2010). This gap in parent's expectation and low supply of good public schools has created space for private parties to step in. These institutions charge high fees for personal gain in exchange for a promise to help a child succeed. This success in determined by the scores in the examination, admission to prestigious higher education institutions and finally being placed in good jobs, all of which would eventually contribute to family's social mobility. The testing culture that places high emphasis on rote memorisation have become the sole determinant of learning. The parents feel that the private parties answer to them because they have paid hefty fees, which is not the case for publically funded schools. The growth and demand for private schools and tuition centres is thus on an all time rise. The flip side is that this expansion of privatisation is far from equitable. It leads to layers of multiple disadvantages and violation of rights of the child (as the child is under constant pressure and has no leisure time), pressure on full time school teachers (who are overburdened with work as they wish to explore ways to procure an extra income while receiving meagre salaries (Majumdar, 2014) and violation of parents' rights (as they have little or no time to spend at home as they are busy trying to raise the household income for paying high fees to private parties). 


\section{EQUITY CONCERNS AND PRIVATE TUTORING}

National Sample Survey (NSS) is a pan India household survey giving details of every household in India. These details include the consumer expenditure, demography, employment information, consumer patterns, etc. One specific nationally representative survey that gives details of private tutoring is the participation and expenditure survey. According to the NSS, household expenditure consists of a very important component of consumer expenditure that includes the private expenditure on education is the sum of all the expenditure a child incurs in education such as school fees, books, stationery, uniform, transport, private tutoring and study tours. The decision to access supplementary tutoring can be understood at two levels. Firstly, whether the children participate in private tutoring and secondly, if they do participate, how much a household spends on private tutoring (Azam, 2015). The equity related questions can further be broken down to the following matters: the privileged section of the society shows the most consumerist characteristic with respect to private tutoring; there is in-equal participation in private tutoring by both genders; the supplementary tutoring institutes are not uniformly spread rural and urban areas; inequalities already existing in the society (like caste, class, gender, region, etc.) do not get addressed in these supplementary coaching centres in any way, at times the inequalities are further deepened as the impact of these private entities. Thus, worsening the inequitable situation of the Indian society. The most important of all these concerns is whether in a state mandated with free and compulsory elementary education for all children private tutoring should even be allowed to exist. Will it not in a way go against the spirit of right to quality education of each and every child irrespective of his/her context and circumstances? These and a few other concerns are dealt with in detail in the following sections.

\section{HOUSEHOLD EXPENDITURE}

Due to the increased belief in school inadequacies and a competing mindset to do well in public examinations, there is a gap in the system which is then filled by private parties in exchange for a fee. Private tutoring refers to a set of educational activities performed outside the formal schooling setup which are designed to improve the students' chances of successfully moving through the school system (Stevenson \& Baker, 2006). It is called private tutoring because the practice is undertaken for private gain of the tutors, i.e. to supplement their incomes with the fees paid by tutees.

The parental expenditure is mainly towards the child's outstanding performance in public examinations. The supplementary education is expected to provide hope to parents for a better future (Sujatha, 2014; Tansel \& Fatma, 2004; Shafiq, 2002). Though recent studies all around the world have quoted the ill effects of private tutoring on the access, equity and quality of education, parents continue to send their wards for this shadow system of education 
(studies cited in Bray, 1999). There are huge costs incurred by the households to send these children to the extra tutoring classes that often lead to significant expenses for the parents.

Data reveals that private tutoring is prevalent in India at every stage of schooling: $20 \%$ at primary level, $13 \%$ middle school and up to an $37.5 \%$ average at all India level (NSS, 2007 to 2008). A share of 43\% of entire private expenditure on education, which is about $16.5 \%$ of household per capita expenditure, is incurred by private tutoring. The burden of per capita consumption expenditure on private tutoring at secondary level is $28.5 \%$ (Azam, 2015). This shows that the demand for private tutoring is inelastic at all stages of schooling. Researchers have now begun to study how the increase in parental income contributes to an increased access to private tutoring, especially in the case of low income families (Das, 2015). It is widely believed that the higher the household income is, the higher the amount spent on private tutoring becomes. Also, as the students progress from primary to secondary to higher secondary, the demand and cost for private tutoring also increases.

\section{GENDERED DECISION TO ACCESS SHADOW EDUCATION}

Researchers have shown a pro-male bias in both the decision to access private schools and tutoring as well as money spent on private tutoring (Azam, 2015; Sujatha \& Rani, 2011; Kingdon, 2005). At primary level, 23\% of male students and $20 \%$ female students receive tutoring whereas this number increases to $38 \%$ and 35\% respectively as student approach higher levels of education (Das, 2015). This gender bias exists mainly in secondary and senior secondary grades. At the secondary stage, a female child is expected to not attend tutoring by $4 \%$ whereas at middle or primary level this probability in only 2.2\% (Azam, 2015).

\section{RIGHTS-BASED DISCOURSE VERSUS PRIVATE TUTORING}

The Right to Education Act of 2009 provides for every child aged 6-14 years to receive free and compulsory education until the completion of elementary education in a neighbourhood school. Moreover, the Section 3(2) states that no child shall be liable to pay any kind of fees or charges that can prevent him/her from pursuing and completing elementary education. RTE of 2009 came with an aim to provide elementary education to all but often scholars like Bray (1999) and Wiseman (2013) have put forward the idea of expansion of education going hand in hand with the private tutoring system. Private supplementary education has been "documented and debated as one of the foremost issues in comparative and international education research in the 20th century" (Wiseman, 2013); its expansion and institutionalisation is predicted to usurp the education phenomena of the 21st century.

In a state with such a strict educational mandate two issues in regard to expansion of private tutoring can be noted: a) Here, the state initiatives are not 
enough to guarantee equity, especially when private self benefitting institutions are present with their very existence based on competition that eliminates the less competent students. b) The scope of the mandate for quality education is restricted to elementary schooling. The law does not include the education of children in secondary and senior secondary stages. This shows that the state assumes that households are responsible for their child's education after elementary grades. T Relating to the first issue, it is a common belief among parents that the children cannot perform well in public examination without supplementary tutoring (Mohanty, 2017). Then, one may wonder what the role of public schools is; have they just been restricted to degree providing bodies? Bray (2009) comments that if private tutoring agencies be given the authority to provide degrees, their existence would be institutionalised and regular schools would no longer exist.

In such a scenario the shadow would become the main body. The state principles of equity and justice get jeopardised as private tutoring becomes more of a choice based decision rather than a right. Quality education is a right when the state has the onus to provide children compulsory education irrespective of their personal capacities and circumstances. Whereas, in a choice based system, access to tutoring is determined by the parents' income and expenditure patterns of the household. Privatisation is rather a market based decision with a very rare focus on equity, especially when in a state like India there are no proper rules, guidelines or mandates for such unrecognised bodies. Here, privatisation means the transfer of assets, management, functions or responsibilities (relating to education) previously owned or carried out by the state to private parties. It occurs when the state institutions leave gaps in their role to provide education and the private parties step in to fill that gap. Thus, it is not an intentional transfer of responsibilities, leaving little or no choice for parents in such situations.

\section{MULTIPLE DISADVANTAGES}

The tutoring system also puts additional burden on the teachers as well as the students. The students often rush to the tutoring with little or no break after school hours and their teachers too have little or no time to relax if they are regular full time school teachers. This leads to a conflict of interest and the school hours often become a time in which these teachers relax as later they have to go and teach private classes. The learning of students not taking tutorials thus suffers. If the teachers are fulltime tutors they might not even possess the required qualification to teach. There is a difference in the kind of tutoring the students receive, e.g. involving star teachers (only teaching in expensive classes) guaranteeing high grades in exams, providing air conditioned classrooms, pick and drop facility, individual home tutoring, etc. This stratification in the kind of tutoring a child can access depends on the financial capacity of the parents, thus, further deepening the gaps that private schools (both lowcost and high-cost) have created. 
Majumdar (2014) argues that supplementary education has become a necessity to assert a low caste social ambition, status symbol and has eventually turned into a social opium. The study points out the ill-effects of private tutoring: excessive, unhealthy competition between students, unbearable pressure on students to perform in examinations, additional financial burden on parents, migration, overemphasis on coaching, exam centred education, dissatisfaction with formal schooling and widening equity concerns, to name a few. There are common expressions of corruption-related concerns i.e. the excessive commercialisation evident in the tutoring market is likely to corrupt non market values that constitute the civic enterprise of education. The study thus aims to examine the growth, scale, causes and consequences of supplementary tutoring. The 'compulsory private tutoring' that school teachers impose on their students raises corruption and degrades the public spirit of education.

In 2007-2008, in urban areas, $27.7 \%$ students attended private tutoring classes and in rural areas, $15.7 \%$ accessed private coaching as per the findings of the 64th Round of 'Participation and Expenditure in Education' Survey administered for 445,960 persons. The cost of private tutoring in urban India (Rs.330) is almost double the cost in rural India (Rs.153) (Sujatha \& Rani, 2011). When the most critical senior secondary years are concerned, $41.2 \%$ children in urban areas who access private schools also access private tutoring classes. This negates the quality claims of private institutions, be it schools or coaching centres. Also, the sole purpose of accessing private tutoring is not in pedagogic in-capabilities of schools; it has more to do with social values attached to private tutoring.

Tapan Mohanty (2017) finds that ambition, worry, fear, distrust in the schooling system, a sense of insecurity and social identity are all contributing factors pushing towards taking private tutoring. In a situation where an individual's social status and social identity are created through the kind of tutoring centre he/she accesses, the most affected in this system are those belonging to socially and economically deprived classes. There are marked differences in expenditure on private tutoring between low income and high income families and between the four major caste groups being considered here: Schedule Tribe (ST), Schedule Caste (SC), Other Backward Caste (OBC) and others (Kumari, 2015; Ireson \& Rushforth, 2014; Majumdar, 2014; Sujatha \& Rani, 2007). In 2007-2008, Non SC(ST) students spent nearly $10.9 \%$ less in private tutoring than non-SC/ST students (Azam, 2015).

Students from the disadvantaged groups cannot afford the expensive shadow system that runs parallel with school setup and thus they suffer further injustice and social exclusion. The lack of availability of large scale pan India organised and comparable data is due to inefficiency of the state to capture this (highly skill-based) unorganised sector. Research done by individuals is insufficient and based on sporadic surveys (Azam, 2015). Agencies such as The Annual Status of Education Report (ASER, 2013) provide data on private tutoring in rural areas but only for the I-VIII grades. It was only in 2013 that ASER started collecting data on the amounts spent by rural households on 
private tutoring. The data related to total private spending by households and socio-economic information of households, the two major equity concerns, remains uncaptured to date.

The above discussion shows that there are many factors that affect equity and inclusion in society. In addition, the cumulative effect of all these factors has a bigger impact on the success of individual and the group. Sujatha and Rani (2011) show that choice of technical subjects, access to private tutoring, place of residence - rural or urban, gender bias, ethnic group one belongs to and the kind of schooling one accesses have lead to a an intersection of disadvantages. The combined effect together leads to the deepening of inequalities.

\section{CONCLUSION}

The increasing level of school examinations, the grade of the child, cost of supplementary tutoring, education level of household heads, probability of being located in urban areas and the probability of being a male child, and the increase in the household income are all closely related to the amount spent on private tutoring. Thus, with the rise in education of individuals through private tutoring, the inequalities also are on an all time increase. On one hand India is moving towards a demand for rise in National Enrolment Rate in school education and higher education to increase through state mandated principles, on the other hand private tutoring has become a necessary item in the household consumption basket.

The non-availability of data in regard to the nature of private tutoring access and socio-economic status of the household raises questions on whether private tutoring is a means to provide remedial help to weak students or a means to maintain and exacerbate the already existing inequalities and differentials in the Indian society. Even after repeated mentions of private supplementary education as not being the correct alternative to bad quality pedagogic practices in schools, a gradual rise was noted from 15.3\% students aged 6-24 accessing private education in 1987-1988 to 18.8\% accessing it in 2007-08 (NSS data cited in Azam, 2015). Ever since, private tutoring has not been in decline; instead, it has experienced a rapid growth. The state needs to recognise the existence of this shadow. The recognition will not only make the structures institutionalised and provide revenue to the state but will also help combat the deepening inequalities. The institutionalisation of the shadow system will make it possible to provide additional support to the marginalised, and initiatives like voucher systems can be taken up to promote access to success. Though equity based approaches to education (like RTE, 2009 \& National Curriculum Framework, 2005) question the existence of a parallel choice-based tutoring system altogether, institutionalization of private tutoring could be aimed to promote some sort of equitable access to all sections of the society. It would open up debates on how supplementary private education is imparted and on the measures to ensure pedagogic sensitivity at large. The aim should not be only to provide 
quality and free education in state-run institutions but to promote equality of opportunity in the society at large. This would also help in teacher accountability and reduction of the pressure on parents. The paper thus argues that (owing to the huge spread of the shadow) instead of questioning the presence of supplementary tutoring and debating on the need of these private systems, a dialogue on making the system more equitable and just should be the aim of the governmental and non-governmental discussions.

\section{REFERENCES}

1. ASER Centre (2013). Annual Status of Education Report. New Delhi.

2. Azam, M. (2016). Private tutoring: evidence from India. Review of Development Economics, 20(4), 739-761.

3. Banks, O. (2013). Parity and prestige in English secondary education. Routledge.

4. Bray, M. (1999). The shadow education system: private tutoring and its implications for planners. Paris: International Institute of Educational Planning. UNESCO.

5. Bray, M. (2003). Adverse Effects of Private Supplementary Tutoring: Dimension, Implications and Government Responses. Paris: International Instituteof Educational Planning, UNESCO.

6. Bray, M. (2009). Confronting the Shadow Education System: What Government

7. Polices for What Private Tutoring? Paris: UNESCO Publishing.

8. Bray, M., \& Lykins, C. (2012). Shadow Education Private Supplementary Tutoring and Its Implications for Policy Makers in Asia. CERC Monograph Series in Comparative and International Education and Development No.9, (Asian Development Bank, 2012). Retrieved from http:/ / www.adb.org (D.O.R. 28/12/2013 08:39pm).

9. Dang, H. A., \& Rogers H. F. (2008). The Growing Phenomenon of Private Tutoring: Does it Deepen Human Capital, Widen Inequalities, or Waste Resources?. The World Bank Research Observer, 23 (2), 2008. Retrieved from http://www.siteresources.worldbank. org (D.O.R.12/12/2011 9:15pm).

10. Das, U. (2015). Private coaching and the impact of the rural employment guarantee programme on it: Evidence from West Bengal, India.

11. David, M. (2007). Equity and diversity: towards a sociology of higher education for the twenty first century?. British Journal of Sociology of Education, 28(5), 675-690.

12. Davies, S. (2004). School choice by default? Understanding the demand for private tutoring in Canada. American Journal of Education, 110(3), 233-255.

13. Devine, F. (2004). Class practices: How parents help their children get good jobs. Cambridge University Press.

14. Ireson, J., \& Rushforth, K. (2014). Why do parents employ private tutors for their children?: Exploring psychological factors that influence demand in England Journal for educational research online, 6(1), 12.

15. Jeffrey, C., Jeffery P., \& Jeffery R. (2004). "A Useless Thing!" or "Nectar of the Gods?" The Cultural Production of Education and Young Men's Struggles for Respect in Liberalizing North India. Annals of the Association of American Geographers. 94.961-981.10.1111/j.1467-8306.2004.00443.x.

16. Kotaky, R., \& Hazarika, M. (2016). IOSR Journal of Research \& Method in Education (IOSR-JRME) e-ISSN: 2320-7388, p-ISSN: 2320-737 Volume VI, Issue 5 Ver. III (September - Oct 2016), PP1925 www.iosrjournals.org. Retrieved from http://www.iosrjournals.org/iosr-jrme/papers/ Vol-6\%20Issue-5/Version 3/D0605031925.pdf (D.O.R. 25/03/2016 2.52pm)

17. Kumari, A. (2015). A study of growth of secondary education in Delhi. InternationalJournal of Social Science Research, 3(1), 1-15.

18. Majumdar, M. (2014). The shadow school system and new class divisions in India. TRG Poverty and Education Working Paper Series Paper, 2.

19. Makworo, G. W. (2012). How can teachers teach effectively without extra tuition? (Unpublished term paper, Kenyatta University). 
20. Mohanty, T. R. (2017). The Socio-Psychological Context of Private Tuition - The Indian Experience. Journal of Educational Planning and Administration, Volume XXXI, No. 1, January 2017, pp. 17- 28.

21. Nafula, N. N. (2002). Achieving a sustainable universal primary Education through debt. (Unpublished PHD. thesis).

22. Nanda, P. K. (2016). Private Tuition thrives in India: NSSO survey. Live mint e-paper, 2016. Retrieved from http://epaper.livemint.com/epaper/viewer.aspx (D.O.R. 23/02/2016 9:04 pm).

23. Rani, G. (2007). Secondary Education in India: Determinants of Development and Performance", NUEPA, 2007. Retrieved from http:/ / www.researchgate.net (D.O.R. 27/07/2015 5.56 pm)

24. Sancho, D. (2015). Youth, Class and Education in Urban India: The year that can break or make you. Routledge.

25. SCERT, West Bengal. Implications of Private Tutoring in west Bengal-A Report, 2009. Retrieved from http:/ / www.scertwestbengal.org (D.O.R. 25/11/2013 7.52pm)

26. Snehi, N. (2010). Private Tuition and its Implications on Quality Secondary Education. Journal of Indian Education, Vol. XXXVI, No. 1, 2010. Retrieved from http:/ / www.ncert.nic.in (D.O.R. 27/07/2015 5.44pm) .

27. Stevenson, D., \& Baker, D. (1992). Shadow education and allocation in formal schooling: transition to university in Japan. American Journal of sociology, 97(6), 1639-57

28. Sujatha, K., \& Geetha Rani P. (2011). Management of Secondary Education in India (New Delhi: Shipra Publications, 2011).

29. Tansel, A., \& Bircan, F. (2006). "Demand for Education in Turkey: A Tobit Analysis of Private Tutoring Expenditures". Economics of Education Review, 25(3): pp. 303-313.

30. Wiseman, W. (2013). "Foreword." In Out of the Shadows: The Global Intensification of Supplementary Education, ed. Janice Aurini, Scott Davies, and Julian Dierkes. Bingley: Emerald. 